\title{
B7-H3 expression in colorectal cancer: associations with clinicopathological parameters and patient outcome
}

Vibeke A Ingebrigtsen ${ }^{1,2^{*}}$, Kjetil Boye ${ }^{1,3}$, Jahn M Nesland ${ }^{2,4}$, Arild Nesbakken ${ }^{2,6}$, Kjersti Flatmark ${ }^{1,5}$ and Øystein Fodstad ${ }^{1,2}$

\begin{abstract}
Background: We have previously reported overexpression of the immunoregulatory protein B7-H3 in colorectal cancer and that nuclear expression predicted poor outcome in colon cancer patients. The present study was performed to examine the prognostic role of $\mathrm{B} 7-\mathrm{H} 3$ in an independent colorectal cancer cohort.

Methods: Using tissue microarrays from 731 colorectal cancer patients, tumour B7-H3 expression was assessed by immunohistochemistry. Associations with clinicopathological parameters and patient outcome were investigated.

Results: Nuclear expression of B7-H3 in cancer cells was present in $27 \%$ of the samples in the total study cohort, while cytoplasmic/membrane and stromal expression was seen in $86 \%$ and $77 \%$ of the samples, respectively. Nuclear B7-H3 had no prognostic relevance in the complete outcome cohort, neither in colon cancer patients. However, nuclear B7-H3 was significantly associated with reduced recurrence-free survival in TNM stage I colorectal cancer patients.

Conclusions: Overexpression of B7-H3 in colorectal cancer was confirmed, but in contrast to previous results, nuclear B7-H3 was not a strong prognostic biomarker in this cohort. The discrepancy might be related to the use of single-core tissue microarrays for detection of the heterogeneously expressed $\mathrm{B} 7-\mathrm{H} 3$, and the role of $\mathrm{B} 7-\mathrm{H} 3$ in colorectal cancer still needs further examination.
\end{abstract}

Keywords: Colorectal cancer, Nuclear B7-H3, Prognostic biomarker, Tissue microarray

\section{Background}

Colorectal cancer (CRC) is a major cause of cancerrelated morbidity and mortality worldwide. Yearly more than one million new cases of CRC are diagnosed and about 600000 patients succumb to the disease, and this makes it the fourth most common cause of cancer deaths [1]. Surgery is the cornerstone treatment for CRC, and while node-positive (TNM III) patients generally profit from adjuvant chemotherapy, no clear survival benefit has been shown for patients with stage I and II disease $[2,3]$. However, tumours within the same stage are biologically and molecularly heterogeneous, and a significant proportion of stage II patients develop metastatic disease despite

\footnotetext{
* Correspondence: vibing@rr-research.no

'Department of Tumor Biology, Norwegian Radium Hospital, Oslo University

Hospital, PO Box 4950, Nydalen, N-0424 Oslo, Norway

${ }^{2}$ Institute for Clinical Medicine, Faculty of Medicine, University of Oslo, PO

Box 1171, Blindern, N-0318 Oslo, Norway

Full list of author information is available at the end of the article
}

apparently curative surgery $[4,5]$. Thus, reliable prognostic biomarkers are needed to complement the TNM system in identifying patients with increased risk of disease recurrence. Great effort has been made to find such markers. Microsatellite instability (MSI) [6-8] and loss of the DCC (Deleted in Colon Cancer) gene [9] are promising candidates, but there is not yet sufficient evidence to apply them in clinical treatment decisions.

$\mathrm{B} 7-\mathrm{H} 3$, an immunoregulatory protein in the B7 family of T cell co-regulatory molecules $[10,11]$, is overexpressed in several different cancer forms including CRC [12-20]. The precise role of B7-H3 in tumour immunity is still ambiguous, as both $\mathrm{T}$ cell co-stimulatory and co-inhibitory effects have been demonstrated [21,22]. Our group has previously demonstrated that $\mathrm{B} 7-\mathrm{H} 3$ silencing conferred reduced metastatic capacity and increased chemosensitivity in both in vitro and in vivo models [23-25], implying that $\mathrm{B} 7-\mathrm{H} 3$ is involved in cancer progression also via non- 
immunological mechanisms. This is supported by the work of Wang et al. and Zhao et al., which showed that knock down of B7-H3 leads to reduced cell migration and invasion [26,27], as well as increased gemcitabine sensitivity [28].

We have previously evaluated B7-H3 expression in nearly 300 CRC whole tissue sections (WTSs) and found that it was expressed in the tumour cell nucleus in about $30 \%$ of the tumours [19]. Interestingly, nuclear localisation of B7-H3 strongly predicted poor outcome in colon cancer, suggesting that nuclear B7-H3 might be considered a new biomarker that could facilitate colon cancer treatment decisions, pending validation of the results in other CRC cohorts. The aim of the present work was therefore to evaluate associations between tumour B7-H3 expression and clinicopathological parameters and patient outcome in an independent cohort of CRC patients.

\section{Methods}

\section{Patient cohort and tissue microarray}

Formalin-fixed, paraffin-embedded tumour tissue was prospectively collected for all patients $(n=939)$ undergoing primary surgery for CRC at Oslo University Hospital-Aker between 1993 and 2003. Registration has been controlled against the Norwegian Cancer Registry. Representative tumour tissue was collected for TMA construction with $1.0 \mathrm{~mm}$ diameter cores. The study was approved by the Regional Committee for Medical and Health Research Ethics (REK1.2005.1629).

Two hundred and eight patients were excluded for the following reasons: not representative or no tumour tissue (183), technically unsuccessful staining (12), unknown disease stage (12), and not primary tumour (1). The total study population thus included 731 patients with histologically verified primary CRC. The outcome study population included 562 patients in TNM stages I-III who had undergone curative surgery, with 402 (72\%) of the tumours localised in the colon and 156 (28\%) in the rectum. Mean patient age at the time of surgery in both the total and the outcome study cohort was 73 years (range: 30-94 years). Colon cancer patients younger than 76 years and all rectal cancer patients entered a 5-year follow-up program. Patients who were not enrolled in systematic follow-up ( $n=353$ ) would be admitted to the hospital for symptoms of relapse, and it is assumed that nearly all relapses would be identified and registered. Further details have previously been described [29].

Recurrence-free survival was measured from the date of surgery until diagnosis of locoregional recurrence or distant metastases within the first 5 years after surgery. Of the 562 patients in the outcome study cohort, 115 patients (20\%) were diagnosed with locoregional recurrence or distant metastasis during this period. Patients without locoregional recurrence or distant metastases were censored at time of death. Overall survival was measured from date of surgery until death. Survival data were obtained from the National Registry of Norway. During the total follow-up period 332 patients passed away. Median follow-up of patients still alive was 9.7 years (range: 5.2 - 17.3 years).

\section{Immunohistochemistry}

Representative cylindrical tissue cores from formalin-fixed and paraffin-embedded colorectal tumours were selected by an experienced colorectal pathologist and collected in a tissue microarray (TMA). The TMA sections were immunostained using the Dako EnVision FLEX + detection system (Dako, Glostrup, Denmark). Dako PT link was used for deparaffinisation and heat-induced epitope retrieval. Sections were preheated in Dako EnVision FLEX + Target Retrieval Solution, High $\mathrm{pH}$, and rinsed in Dako wash buffer according to the manufacturer's instructions. Endogenous peroxidase activity was blocked with EnVision FLEX Peroxidase-Blocking Reagent, before incubation with mouse monoclonal anti-human B7-H3 antibody (Clone MIH42, LifeSpan BioSciences, Seattle, WA), at 1:300 for 30 minutes at room temperature. The primary antibody signal was amplified by EnVision FLEX + Mouse (LINKER) before incubation with EnVision FLEX/HRP Detection Reagent for 30 minutes. Finally, the sections were incubated with diaminobenzene before they were counterstained with hematoxylin, rinsed and mounted in Cytoseal XYL (Thermo Scientific, Waltham, MA). Negative controls included replacement of the primary antibody with normal polyclonal mouse IgG of the same subclass and concentration, and incubations of sections with mouse monoclonal anti-B7-H3 antibody pre-absorbed with $10 \mu \mathrm{g} / \mathrm{ml}$ recombinant human B7-H3 (R\&D Systems, Minneapolis, MN). Positive controls (sections from formalinfixed and paraffin-embedded colorectal tumour tissue known to express high amounts of B7-H3) were included in all series.

The immunostained TMAs were scored microscopically by the study pathologist (J.M.N), without knowledge of patient outcome or corresponding clinicopathological parameters. Nuclear staining in tumour cells was recorded as an individual variable. As membrane positive tumour cells typically displayed cytoplasmic staining as well, cytoplasmic and membrane staining were recorded as one variable, as were staining of tumour-associated fibroblasts and endothelial cells. Nuclear and stromal staining was scored as negative (no staining) or positive (nuclear/ stromal staining present). Cytoplasmic and membrane staining was semi-quantitatively estimated, and graded as 0 (no staining), 1 (less than $10 \%$ positive cells), 2 (10-49\% positive cells) or 3 (more than $50 \%$ positive cells). For the statistical analyses the cytoplasmic/membrane B7-H3 scores were divided into negative (no staining) and 
positive staining (cytoplasmic/membrane staining present). The rationale for choosing this cut-off is that the TMA cores only comprise a small section of the tumour, and even a few positive cells in the core indicate a $\mathrm{B} 7-\mathrm{H} 3$ positive tumour.

\section{Statistical analysis}

Associations between B7-H3 expression and clinicopathological parameters were analysed using two-tailed Fisher's exact test or linear-by-linear association chi-square test. Survival analysis was performed according to the KaplanMeier method, and survival was compared using the log rank test. The SPSS version 18.0 software (SPSS, Chicago, IL) was used for statistical calculations. P-values below 0.05 were considered statistically significant. Five patients had duplicate cores and of these, three had contradictory nuclear B7-H3 score in the two cores. Scoring these three patients as nuclear positive or negative or excluding them from statistical analysis did not significantly influence results, and in the presented results, nuclear score was set to positive for these cases. For 5 patients in the total study cohort and 4 patients in the outcome study cohort tumour localisation was not known, and these were excluded from statistical analyses involving tumour localisation.

\section{Results}

Patient characteristics

Clinical and pathological features for the total and the outcome study population are summarised in Table 1. The total study cohort included 389 (53\%) females and $342(47 \%)$ males. The majority of the patients was in TNM stage II (307/42\% in the total study cohort and $287 /$ $51 \%$ in the outcome study cohort), had pT3 tumours (73\% in both cohorts) and no lymph node metastases (63 and $69 \%$, respectively). Most tumours were intermediately differentiated (78\% in both cohorts). In both cohorts 103 patients had TNM stage I disease.

\section{B7-H3 expression in primary colorectal carcinomas}

The immunohistochemical expression levels of $\mathrm{B} 7-\mathrm{H} 3$ are shown in Table 1, and representative microscope images are shown in Figure 1. The majority of tumours displayed cytoplasmic/membrane staining (Figure 1A and B) (86\% in the total study cohort), as well as stromal staining (Figure 1A) (77\% in the total study cohort). Nuclear staining was seen in $27 \%$ of the evaluated samples in the total study cohort (Figure 1B and C).

\section{Associations between B7-H3 expression and clinicopathological parameters}

No significant associations were found between cancer cell B7-H3 expression and clinicopathological parameters, as shown in Table 2. However, absence of stromal B7-H3 expression was associated with advanced TNM stage
Table 1 Baseline clinicopathological data and tumour expression of B7-H3

\begin{tabular}{|c|c|c|c|c|c|}
\hline \multirow[b]{3}{*}{ Parameter } & & \multirow{2}{*}{\multicolumn{2}{|c|}{$\begin{array}{c}\begin{array}{c}\text { Total study } \\
\text { cohort }\end{array} \\
\text { Patients }\end{array}$}} & \multirow{2}{*}{\multicolumn{2}{|c|}{$\begin{array}{c}\begin{array}{c}\text { Outcome study } \\
\text { cohort }\end{array} \\
\text { Patients }\end{array}$}} \\
\hline & & & & & \\
\hline & & Number & $\%$ & Number & $\%$ \\
\hline \multirow[t]{2}{*}{ Gender } & Female & 389 & 53 & 292 & 52 \\
\hline & Male & 342 & 47 & 270 & 48 \\
\hline \multirow[t]{4}{*}{ TNM stage } & । & 103 & 14 & 103 & 18 \\
\hline & $\|$ & 307 & 42 & 287 & 51 \\
\hline & III & 186 & 25 & 172 & 31 \\
\hline & IV & 135 & 18 & - & - \\
\hline \multirow[t]{4}{*}{ pT } & 1 & 27 & 4 & 26 & 5 \\
\hline & 2 & 98 & 13 & 94 & 17 \\
\hline & 3 & 534 & 73 & 410 & 73 \\
\hline & 4 & 72 & 10 & 32 & 6 \\
\hline \multirow[t]{4}{*}{$\mathrm{pN}$} & 0 & 455 & 63 & 389 & 69 \\
\hline & 1 & 197 & 27 & 135 & 24 \\
\hline & 2 & 74 & 10 & 37 & 7 \\
\hline & ND & 5 & - & 1 & - \\
\hline \multirow[t]{4}{*}{ Differentiation } & Well & 72 & 10 & 66 & 12 \\
\hline & Intermediate & 549 & 78 & 426 & 78 \\
\hline & Poor & 87 & 12 & 55 & 10 \\
\hline & ND & 23 & - & 15 & - \\
\hline \multirow[t]{3}{*}{ Tumour localisation } & Colon & 546 & 75 & 402 & 72 \\
\hline & Rectum & 180 & 25 & 156 & 28 \\
\hline & Unknown & 5 & - & 4 & - \\
\hline \multirow{4}{*}{$\begin{array}{l}\text { Cytoplasmic/ } \\
\text { membrane B7-H3 }\end{array}$} & 0 & 104 & 14 & 74 & 13 \\
\hline & 1 & 79 & 11 & 44 & 8 \\
\hline & 2 & 124 & 17 & 101 & 18 \\
\hline & 3 & 424 & 58 & 343 & 61 \\
\hline \multirow[t]{2}{*}{ Nuclear B7-H3 } & 0 & 534 & 73 & 400 & 71 \\
\hline & 1 & 197 & 27 & 162 & 29 \\
\hline \multirow[t]{2}{*}{ Total $^{1}$ B7-H3 } & 0 & 94 & 13 & 66 & 12 \\
\hline & 1 & 637 & 87 & 496 & 88 \\
\hline \multirow[t]{2}{*}{ Stromal B7-H3 } & 0 & 171 & 23 & 121 & 22 \\
\hline & 1 & 560 & 77 & 441 & 78 \\
\hline
\end{tabular}

Abbreviations: $N D$ not determined, $p N$ pathological nodal stage, $p T$ pathological tumour stage, $T N M$ tumour node metastasis.

${ }^{1}$ Nuclear, and/or cytoplasmic/membrane staining.

$(\mathrm{p}=0.03)$ and the presence of lymph node metastases $\mathrm{pN}(\mathrm{p}=0.007)$. We did not observe any differences in B7-H3 expression in colon versus rectal cancer.

\section{Associations between clinicopathological parameters and} outcome

The prognostic significance of clinicopathological parameters was investigated by univariate analysis (Table 3 ). 


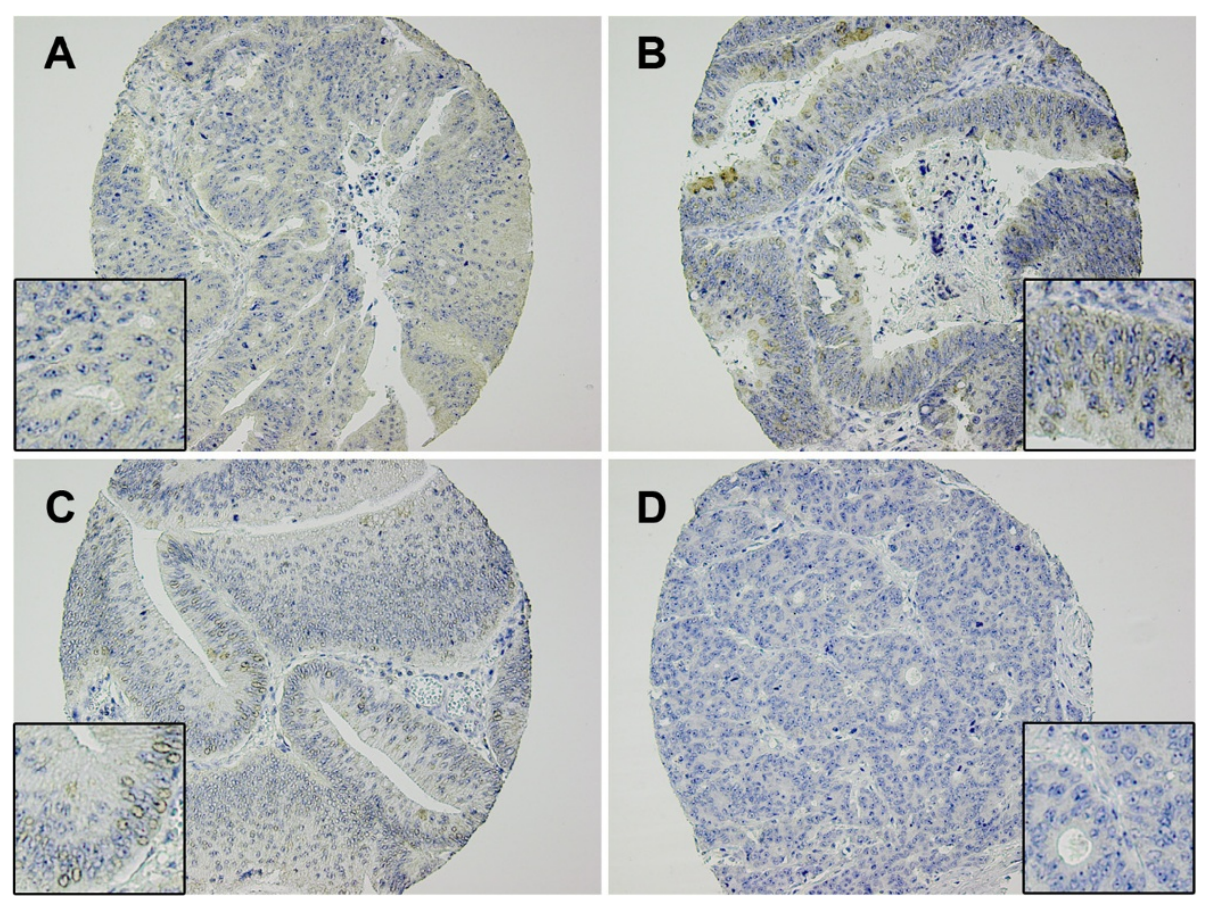

Figure 1 Representative photomicrographs of colorectal cancer TMA specimens stained with anti-B7-H3 antibody. Panel A shows predominantly cytoplasmic and stromal staining, panel $\mathbf{B}$ shows nuclear and cytoplasmic staining, panel $\mathbf{C}$ shows nuclear staining and panel D shows a B7-H3 negative tumour.

Advanced TNM stage, T classification and nodal status were significantly associated with the development of locoregional recurrence or distant metastases within the first 5 years after surgery. There was a tendency towards increased recurrence-free survival for colon cancer patients versus rectal cancer patients, but it did not reach statistical significance $(p=0.13)$. In accordance with the results for recurrence-free survival, TNM stage, $\mathrm{pT}$ and $\mathrm{pN}$ were also significantly associated with overall survival.

\section{Associations between B7-H3 expression and patient outcome}

Univariate analysis did not display significant associations between $\mathrm{B} 7-\mathrm{H} 3$ expression and patient outcome in CRC patients (Table 3). In contrast to what was found in the previous WTS study nuclear B7-H3 had no prognostic relevance in the complete outcome cohort ( $p=0.62$ for recurrence-free survival and 0.5 for overall survival), neither when analysing colon $(\mathrm{p}=0.88$ for recurrence-free survival and 0.64 for overall survival) and rectal patients ( $\mathrm{p}=0.5$ and 0.52 , respectively) separately (Figure 2). However, in TNM stage I patients there was a strong association between the presence of nuclear B7-H3 expression and reduced recurrence-free survival $(\mathrm{p}=0.006$, Figure 3$)$, but not with overall survival $(\mathrm{p}=$ 0.57 , data not shown).

\section{Simulated tissue microarray cores from whole tissue sections}

As the previously observed prognostic significance of nuclear B7-H3 staining could not be confirmed in the present TMA cohort, we wanted to assess whether the use of TMAs instead of WTSs to evaluate tumour B7H3 expression might have affected the results, and we looked in more detail at the nuclear expression pattern in a few of the old WTS sections. Figure 4 shows B7-H3 immunohistochemical staining in two simulated TMA cores from distinct segments of the WTSs from patient 16 and 30 in the WTS cohort. As is evident in the images, there is considerable heterogeneity of nuclear B7-H3 expression in the depicted CRC tumour samples, and the selection of two morphologically representative cores from each tumour resulted in opposite nuclear B7-H3 score. This example clearly demonstrates the inherent problem in obtaining TMA cores representative for the entire tumour.

\section{Discussion}

We have previously reported that nuclear $\mathrm{B} 7-\mathrm{H} 3$ protein expression was strongly and independently associated with poor prognosis in colon cancer patients [19]. In the present work we examined immunohistochemical expression of B7-H3 in TMAs prepared from a large panel of colorectal carcinomas, and evaluated the associations 
Table 2 Associations between B7-H3 expression and clinicopathological parameters - total study cohort

\begin{tabular}{|c|c|c|c|c|c|c|}
\hline Parameter & & $\begin{array}{l}\text { Patients number } \\
(\%)\end{array}$ & $\begin{array}{c}\text { Cytoplasmic/membrane } \\
\text { B7-H3 }\end{array}$ & $\begin{array}{c}\text { Nuclear } \\
\text { B7-H3 }\end{array}$ & $\begin{array}{l}\text { Total }^{1} \\
\text { B7-H3 } \\
\end{array}$ & $\begin{array}{c}\text { Stromal } \\
\text { B7-H3 }\end{array}$ \\
\hline \multirow[t]{3}{*}{ Gender } & Male & $342(47)$ & $298(87)$ & $92(27)$ & $303(89)$ & $269(79)$ \\
\hline & Female & $389(53)$ & $329(85)$ & $105(27)$ & $334(86)$ & $291(75)$ \\
\hline & $p$-value & & 0.34 & 1.0 & 0.32 & 0.26 \\
\hline \multirow[t]{5}{*}{ TNM } & I & $103(14)$ & $88(85)$ & $33(32)$ & $89(86)$ & $79(77)$ \\
\hline & $\|$ & 307 (42) & $268(87)$ & $78(25)$ & $272(89)$ & $250(81)$ \\
\hline & III & $186(25)$ & $161(87)$ & $58(31)$ & $165(89)$ & $137(74)$ \\
\hline & IV & 135 (18) & $110(81)$ & $28(21)$ & $111(82)$ & $94(70)$ \\
\hline & $p$-value & & 0.29 & 0.22 & 0.27 & 0.03 \\
\hline \multirow[t]{5}{*}{ pT } & 1 & $27(4)$ & $20(74)$ & $9(33)$ & $22(81)$ & $20(74)$ \\
\hline & 2 & $98(13)$ & $86(88)$ & $32(33)$ & $86(88)$ & $73(74)$ \\
\hline & 3 & $534(73)$ & $463(87)$ & $135(25)$ & $471(88)$ & $419(78)$ \\
\hline & 4 & $72(10)$ & $58(81)$ & $21(29)$ & $58(81)$ & $48(67)$ \\
\hline & $p$-value & & 0.93 & 0.34 & 0.72 & 0.62 \\
\hline \multirow[t]{4}{*}{$\mathrm{pN}$} & 0 & $455(63)$ & $393(86)$ & $119(26)$ & $398(87)$ & $363(80)$ \\
\hline & 1 & $197(27)$ & $169(86)$ & $61(31)$ & $173(88)$ & $147(75)$ \\
\hline & 2 & $74(10)$ & $62(84)$ & $16(22)$ & $63(85)$ & $49(66)$ \\
\hline & $p$-value & & 0.58 & 1.0 & 0.74 & 0.007 \\
\hline \multirow[t]{4}{*}{ Differentiation } & Well & $72(10)$ & $62(86)$ & $25(35)$ & $63(88)$ & $54(75)$ \\
\hline & Intermediate & $549(78)$ & $469(85)$ & $144(26)$ & $477(87)$ & $423(77)$ \\
\hline & Poor & $87(12)$ & $74(85)$ & $22(25)$ & $75(86)$ & $67(77)$ \\
\hline & $p$-value & & 0.91 & 0.21 & 0.82 & 0.85 \\
\hline \multirow[t]{3}{*}{ Tumour localisation ${ }^{2}$} & Colon & $546(75)$ & $473(87)$ & $150(27)$ & $481(88)$ & $417(76)$ \\
\hline & Rectum & $180(25)$ & $150(83)$ & $46(26)$ & $152(84)$ & $141(78)$ \\
\hline & $p$-value & & 0.34 & 0.7 & 0.2 & 0.61 \\
\hline
\end{tabular}

The table shows the number/percent of patients in each subcategory, the number/percent of B7-H3 positive patients in each subcategory as well as the $p$-value resulting from statistical analysis of associations between $\mathrm{B} 7-\mathrm{H} 3$ expression and each parameter.

${ }^{1}$ Nuclear and/or cytoplasmic/membrane staining.

${ }^{2}$ Five patients had unknown tumour localisation, these were excluded from the statistical analyses involving tumour localisation.

Table 3 Associations between survival and clinicopathological parameters and B7-H3 expression

\begin{tabular}{lcc}
\hline & \multicolumn{2}{c}{$\begin{array}{c}\text { Univariate analysis } \\
\text { (P-value, log rank test) }\end{array}$} \\
\cline { 2 - 3 } $\begin{array}{l}\text { Recurrence-free } \\
\text { survival }\end{array}$ & $\begin{array}{c}\text { Overall } \\
\text { survival }\end{array}$ \\
\hline Gender & 0.26 & 0.34 \\
TNM stage & $<0.001$ & $<0.001$ \\
pT & $<0.001$ & $<0.001$ \\
pN & $<0.001$ & $<0.001$ \\
Differentiation & 0.58 & 0.38 \\
Tumour localisation ${ }^{1}$ & 0.13 & 0.33 \\
Cytoplasmic/Membrane B7-H3 & 0.25 & 0.82 \\
Nuclear B7-H3 & 0.62 & 0.50 \\
Total $^{2}$ B7-H3 & 0.24 & 0.90 \\
Stromal B7-H3 $^{2}$ & 0.43 & 0.84 \\
\hline
\end{tabular}

${ }^{1}$ Five patients had unknown tumour localisation, these were excluded from the statistical analyses involving tumour localisation.

${ }^{2}$ Nuclear and/or cytoplasmic/membrane staining. between $\mathrm{B} 7-\mathrm{H} 3$ expression, clinicopathological parameters and patient outcome. The main objective was to investigate whether the results from our previous study could be validated in an independent $\mathrm{CRC}$ cohort.

In the present work, nuclear B7-H3 was significantly associated with reduced recurrence-free survival in TNM I patients only, contrasting the previous study in which nuclear B7-H3 was significantly and independently associated with reduced metastasis-free and overall survival in colon cancer patients. The inconsistency between present and previous results on the prognostic impact of nuclear B7-H3 may have several possible explanations. Differences between the two examined CRC patient cohorts could exist, but both were prospectively established from patients undergoing surgery for primary CRC within the same time period, and with no substantial differences in cohort composition (Additional file 1: Table S1). There was, however, a critical methodological difference between the two studies, since TMAs were used in the present 


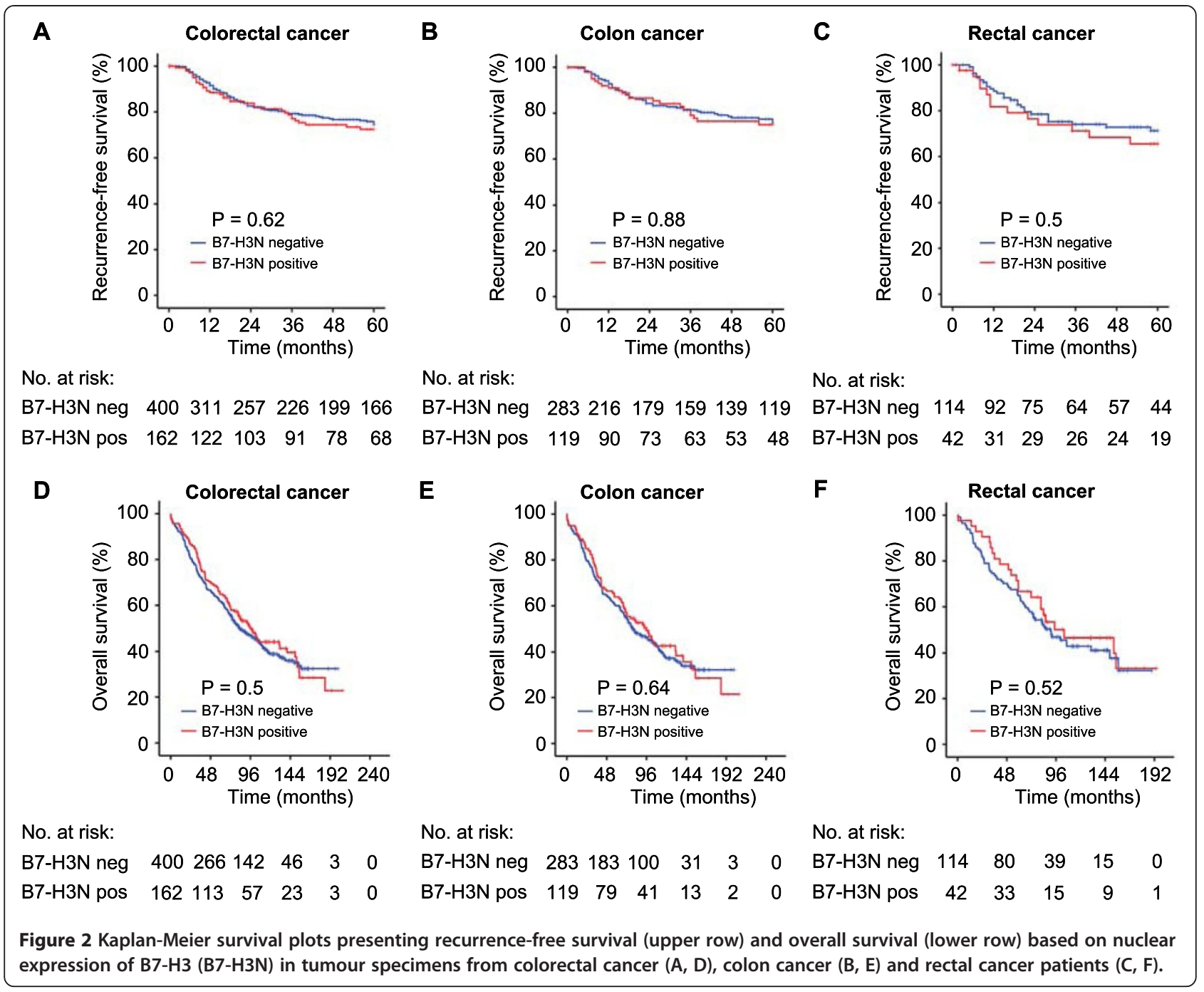

work compared to WTSs in the previous one. The use of single, small cores for TMA construction may not be representative of large tumours in the colorectum, in particular when the protein of interest exhibits significant expression heterogeneity $[30,31]$. Using the simulated TMAs as examples, we show that because of heterogeneity of nuclear B7-H3 expression in the CRC tumour samples, conclusions regarding nuclear $\mathrm{B} 7-\mathrm{H} 3$ status partially depend on where the core was taken. Similar results have been demonstrated in a study comparing WTSs and TMAs in clear cell renal cell carcinoma using simulated TMAs. The number of cores required to adequately represent WTS quantification was shown to be biomarker specific, and for B7-H3 2-3 cores appeared necessary [32]. Thus, although the present cohort represents a large, well-characterized population-based collection of CRC specimens, heterogeneous expression of the protein of interest rendered the single-core TMA approach questionable in this setting, and this represents a limitation for the interpretation of the results.
In both the previous and the present study nuclear B7-H3 staining was detected in nearly one third of the evaluated tumour samples. While nuclear expression of B7-H3 in tumour cells so far has been reported by our group only, several authors have described the prognostic impact of tumour B7-H3 expression in various other cancer forms. The results are highly variable and even conflicting: Most reports indicate that high tumour B7-H3 level is associated with advanced disease and/or poor outcome $[13,14,16,17,20,33,34]$. Some investigators report no associations between tumour $\mathrm{B} 7-\mathrm{H} 3$ and prognosis $[35,36]$, and some that high tumour B7-H3 expression is associated with improved outcome [12,15]. Taken together, this indicates that the role of $\mathrm{B} 7-\mathrm{H} 3$ as a prognostic marker in cancer in general is undetermined. Though the inconsistent findings might be due to methodological issues it could also be that B7-H3 has different prognostic and functional roles in different cancer forms.

Nuclear B7-H3 was associated with poor outcome in TNM I patients in this cohort, and the strongest association 


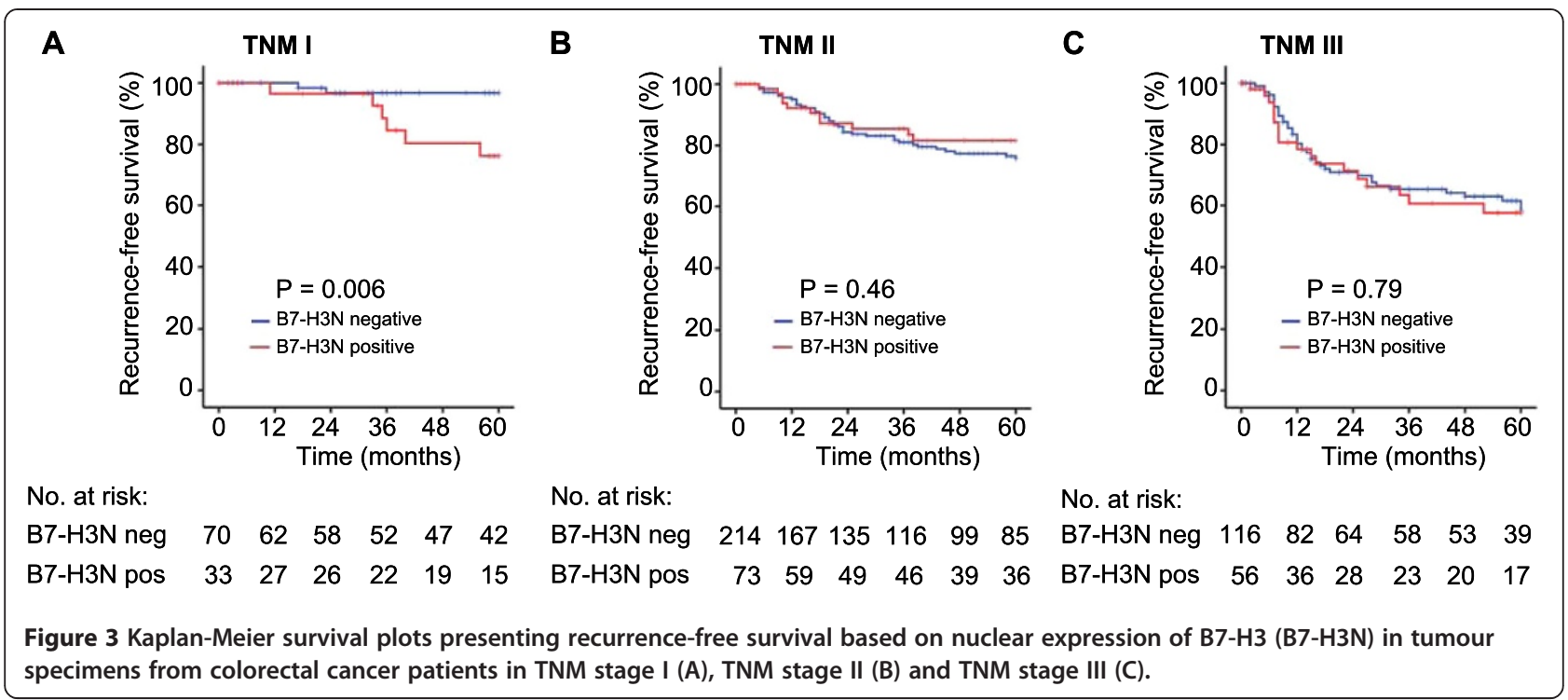

between nuclear B7-H3 and reduced survival in the previous cohort was seen in TNM II patients. This might hypothetically point to nuclear $\mathrm{B} 7-\mathrm{H} 3$ as a possible promoter of progression and metastasis in early stages of CRC. It is well known that cancer associated proteins can have diverse roles in the different stages of cancer progression [37,38]. Additionally, differences regarding the expression level and distribution of a protein between cancer cells and stromal cells in a tumour may reflect shifts in biological effects. Hence, that absent stromal B7-H3 was associated with advanced disease stage at diagnosis might be of some interest. $\mathrm{T}$ cell co-stimulatory effects of B7-H3 have been demonstrated, and theoretically tumours lacking stromal B7-H3 could escape anti-tumour immunity which would otherwise impede disease progression [39,40]. On the other hand, B7-H3 suppression of anti-tumour immunity has also

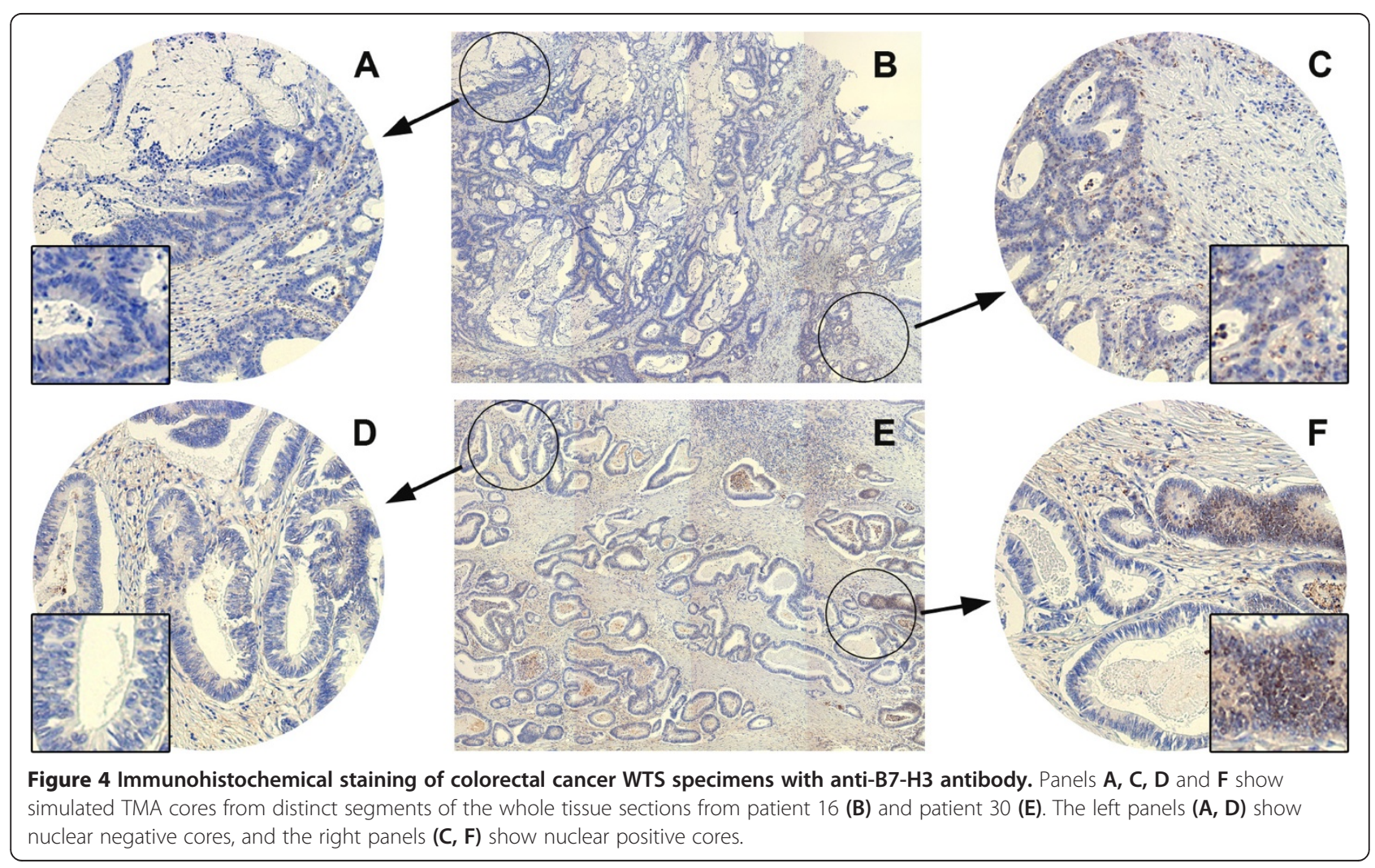


been reported $[18,41,42]$, leaving the immunomodulatory role of $\mathrm{B} 7-\mathrm{H} 3$ in this setting unclear. Another hypothesis could be that stromal B7-H3 restrains disease progression through so far unknown non-immunological mechanisms. Despite uncertainty regarding the clinical implications of nuclear and stromal B7-H3 in CRC, our findings may be important to consider in future studies.

\section{Conclusions}

Nuclear B7-H3 was not a strong prognostic biomarker in CRC in the present study, contrasting previous findings by our group. Because of heterogeneous expression of nuclear B7-H3, the use of single-core TMAs instead of WTSs in the present study may have influenced the results. However, our results and the findings of other groups might indicate that hypothetically the biological role of B7-H3 may differ from one tumour type to another, may change during disease progression, and furthermore that the protein might attain different functions dependent on cell type, microenvironment and subcellular localisation. Together with data indicating that B7-H3 promotes cancer progression through modulation of important signaling pathways [24,25] this calls for further investigation.

\section{Additional file}

\section{Additional file 1: Clinicopathological parameters and B7-H3 expression,} WTS and TMA cohorts (outcome study cohorts).

\section{Abbreviations}

CRC: Colorectal cancer; DCC: Deleted in colon cancer; MSI: Microsatellite instability; TMA: Tissue microarray; TNM: Tumour node metastasis; WTS: Whole tissue section.

\section{Competing interests}

The authors declare that they have no competing interests.

\section{Authors' contributions}

VAl conceived the study, performed data analysis and wrote the manuscript KB participated in data analysis and contributed with critical revisions of the manuscript. JMN evaluated the immunostained sections. AN provided patient material and patient data. KF contributed with critical revisions of the manuscript. ØF conceived the study and participated in writing the manuscript. All authors read and approved the final manuscript.

\section{Acknowledgements}

The authors are grateful to Professor Ragnhild A. Lothe for kindly providing the tissue microarray sections of the colorectal cancer series, and to Professor Aud Svindland for her effort in establishing the panel. We also would like to thank Ellen Hellesylt for excellent technical assistance and Dr. Hari Prasad Dhakal for kindly determining the optimal antibody dilution. This work was supported by the Faculty of Medicine, University of Oslo and by the South-Eastern Norway Regional Health Authority.

\section{Author details}

'Department of Tumor Biology, Norwegian Radium Hospital, Oslo University Hospital, PO Box 4950, Nydalen, N-0424 Oslo, Norway. Institute for Clinical Medicine, Faculty of Medicine, University of Oslo, PO Box 1171, Blindern, N-0318 Oslo, Norway. ${ }^{3}$ Department of Oncology, Norwegian Radium Hospital, Oslo University Hospital, PO Box 4950, Nydalen, N-0424 Oslo, Norway. ${ }^{4}$ Department of Pathology, Norwegian Radium Hospital, Oslo
University Hospital, PO Box 4950, Nydalen, N-0424 Oslo, Norway. ${ }^{5}$ Department of Gastroenterological Surgery, Norwegian Radium Hospital, Oslo University Hospital, PO Box 4950, Nydalen, N-0424 Oslo, Norway. ${ }^{6}$ Department of Gastrointestinal Surgery, Oslo University Hospital - Aker, PO Box 4950, Nydalen, N-0424 Oslo, Norway.

Received: 12 September 2013 Accepted: 30 July 2014 Published: 20 August 2014

\section{References}

1. Ferlay J, Shin HR, Bray F, Forman D, Mathers C, Parkin DM: Estimates of worldwide burden of cancer in: GLOBOCAN 2008. Int J Cancer 2008, 2010(127):2893-2917.

2. Gray R, Barnwell J, McConkey C, Hills RK, Williams NS, Kerr DJ: Adjuvant chemotherapy versus observation in patients with colorectal cancer: a randomised study. Lancet 2007, 370:2020-2029.

3. Andre T, Boni C, Navarro M, Tabernero J, Hickish T, Topham C, Bonetti A, Clingan P, Bridgewater J, Rivera F, de Gramont A: Improved overall survival with oxaliplatin, fluorouracil, and leucovorin as adjuvant treatment in stage II or III colon cancer in the MOSAIC trial. J Clin Oncol 2009, 27:3109-3116.

4. Kapiteijn E, Marijnen CA, Nagtegaal ID, Putter H, Steup WH, Wiggers T, Rutten HJ, Pahlman L, Glimelius B, van Krieken JH, Leer JW, van de Velde CJ, Dutch Colorectal Cancer Group: Preoperative radiotherapy combined with total mesorectal excision for resectable rectal cancer. N Engl J Med 2001, 345:638-646.

5. O'Connell JB, Maggard MA, Ko CY: Colon cancer survival rates with the new American Joint Committee on Cancer sixth edition staging. J Natl Cancer Inst 2004, 96:1420-1425.

6. Gryfe R, Kim H, Hsieh ET, Aronson MD, Holowaty EJ, Bull SB, Redston M, Gallinger S: Tumor microsatellite instability and clinical outcome in young patients with colorectal cancer. N Engl J Med 2000, 342:69-77.

7. Kohonen-Corish MR, Daniel JJ, Chan C, Lin BP, Kwun SY, Dent OF, Dhillon VS, Trent RJ, Chapuis PH, Bokey EL: Low microsatellite instability is associated with poor prognosis in stage C colon cancer. J Clin Oncol 2005, 23:2318-2324.

8. Malesci A, Laghi L, Bianchi P, Delconte G, Randolph A, Torri V, Carnaghi C, Doci R, Rosati R, Montorsi M, Roncalli M, Gennari L, Santoro A: Reduced likelihood of metastases in patients with microsatellite-unstable colorectal cancer. Clin Cancer Res 2007, 13:3831-3839.

9. Popat S, Houlston RS: A systematic review and meta-analysis of the relationship between chromosome $18 \mathrm{q}$ genotype, DCC status and colorectal cancer prognosis. Eur J Cancer 2005, 41:2060-2070.

10. Chapoval Al, Ni J, Lau JS, Wilcox RA, Flies DB, Liu D, Dong H, Sica GL, Zhu G, Tamada K, Chen L: B7-H3: a costimulatory molecule for T cell activation and IFN-gamma production. Nat Immunol 2001, 2:269-274.

11. Collins M, Ling V, Carreno BM: The B7 family of immune-regulatory ligands. Genome Biol 2005, 6:223.

12. Wu CP, Jiang JT, Tan M, Zhu YB, Ji M, Xu KF, Zhao JM, Zhang GB, Zhang XG: Relationship between co-stimulatory molecule B7-H3 expression and gastric carcinoma histology and prognosis. World J Gastroenterol 2006, 12:457-459.

13. Zang X, Thompson RH, Al-Ahmadie HA, Serio AM, Reuter VE, Eastham JA, Scardino PT, Sharma P, Allison JP: B7-H3 and B7x are highly expressed in human prostate cancer and associated with disease spread and poor outcome. Proc Natl Acad Sci U S A 2007, 104:19458-19463.

14. Crispen PL, Sheinin $Y$, Roth TJ, Lohse CM, Kuntz SM, Frigola X, Thompson RH, Boorjian SA, Dong H, Leibovich BC, Blute ML, Kwon ED: Tumor cell and tumor vasculature expression of $\mathrm{B} 7-\mathrm{H} 3$ predict survival in clear cell renal cell carcinoma. Clin Cancer Res 2008, 14:5150-5157.

15. Loos M, Hedderich DM, Ottenhausen M, Giese NA, Laschinger M, Esposito I, Kleeff J, Friess $\mathrm{H}$ : Expression of the costimulatory molecule B7-H3 is associated with prolonged survival in human pancreatic cancer. BMC Cancer 2009, 9:463.

16. Yamato I, Sho M, Nomi T, Akahori T, Shimada K, Hotta K, Kanehiro H, Konishi N, Yagita H, Nakajima Y: Clinical importance of B7-H3 expression in human pancreatic cancer. Br J Cancer 2009, 101:1709-1716.

17. Arigami T, Narita N, Mizuno R, Nguyen L, Ye X, Chung A, Giuliano AE, Hoon DS: B7-h3 ligand expression by primary breast cancer and associated with regional nodal metastasis. Ann Surg 2010, 252:1044-1051. 
18. Sun J, Chen $L$, Zhang GB, Jiang JT, Zhu M, Tan Y, Wang HT, Lu BF, Zhang $X G$ : Clinical significance and regulation of the costimulatory molecule B7-H3 in human colorectal carcinoma. Cancer Immunol Immunother 2010 59:1163-1171.

19. Ingebrigtsen VA, Boye K, Tekle C, Nesland JM, Flatmark K, Fodstad O: B7-H3 expression in colorectal cancer: nuclear localization strongly predicts poor outcome in colon cancer. Int J Cancer 2012, 131:2528-2536.

20. Sun T-W, Gao Q, Qiu S-J, Zhou J, Wang X-Y, Yi Y, Shi J-Y, Xu Y-F, Shi Y-H, Song K, Xiao YS, Fan J: B7-H3 is expressed in human hepatocellular carcinoma and is associated with tumor aggressiveness and postoperative recurrence. Cancer Immunol Immunother 2012, 61:2171-2182.

21. Hofmeyer KA, Ray A, Zang X: The contrasting role of B7-H3. Proc Natl Acad Sci U S A 2008, 105:10277-10278.

22. Loos M, Hedderich DM, Friess $H$, Kleeff J: B7-h3 and its role in antitumor immunity. Clin Dev Immunol 2010, 2010:683875.

23. Chen YW, Tekle C, Fodstad O: The immunoregulatory protein human $\mathrm{B} 7 \mathrm{H} 3$ is a tumor-associated antigen that regulates tumor cell migration and invasion. Curr Cancer Drug Targets 2008, 8:404-413.

24. Liu H, Tekle C, Chen YW, Kristian A, Zhao Y, Zhou M, Liu Z, Ding Y, Wang B, Maelandsmo GM, Nesland JM, Fodstad O, Tan M: B7-H3 silencing increases paclitaxel sensitivity by abrogating Jak2/Stat3 phosphorylation. Mol Cancer Ther 2011, 10(6):960-971. doi:10.1158/1535-7163.MCT-11-0072. Epub 2011 Apr 25.

25. Tekle C, Nygren MK, Chen YW, Dybsjord I, Nesland JM, Maelandsmo GM, Fodstad O: B7-H3 contributes to the metastatic capacity of melanoma cells by modulation of known metastasis-associated genes. Int J Cancer 2011, 130(10):2282-2290. doi:10.1002/ijc.26238. Epub 2011 Aug 8.

26. Wang J, Chong KK, Nakamura Y, Nguyen L, Huang SK, Kuo C, Zhang W, Yu H, Morton DL, Hoon DS: B7-H3 Associated with Tumor Progression and Epigenetic Regulatory Activity in Cutaneous Melanoma. J Invest Dermatol 2013, 133(8):2050-2058. doi:10.1038/jid.2013.114. Epub 2013 Mar 8.

27. Zhao X, Li DC, Zhu XG, Gan WJ, Li Z, Xiong F, Zhang ZX, Zhang GB, Zhang $X G$, Zhao H: B7-H3 overexpression in pancreatic cancer promotes tumor progression. Int J Mol Med 2013, 31:283-291.

28. Zhao X, Zhang GB, Gan WJ, Xiong F, Li Z, Zhao H, Zhu DM, Zhang B, Zhang XG, Li DC: Silencing of B7-H3 increases gemcitabine sensitivity by promoting apoptosis in pancreatic carcinoma. Oncol Lett 2013, 5:805-812.

29. Merok MA, Ahlquist T, Royrvik EC, Tufteland KF, Hektoen M, Sjo OH, Mala T, Svindland A, Lothe RA, Nesbakken A: Microsatellite instability has a positive prognostic impact on stage II colorectal cancer after complete resection: results from a large, consecutive Norwegian series. Ann Oncol 2013, 24:1274-1282.

30. lakovlev W, Pintilie M, Morrison A, Fyles AW, Hill RP, Hedley DW: Effect of distributional heterogeneity on the analysis of tumor hypoxia based on carbonic anhydrase IX. Lab Invest 2007, 87:1206-1217.

31. Linderoth J, Ehinger M, Akerman M, Cavallin-Stahl E, Enblad G, Erlanson M, Jerkeman M: Tissue microarray is inappropriate for analysis of BCL6 expression in diffuse large B-cell lymphoma. Eur J Haematol 2007, 79:146-149.

32. Eckel-Passow JE, Lohse CM, Sheinin Y, Crispen PL, Krco CJ, Kwon ED: Tissue microarrays: one size does not fit all. Diagn Pathol 2010, 5:48.

33. Roth TJ, Sheinin Y, Lohse CM, Kuntz SM, Frigola X, Inman BA, Krambeck AE, McKenney ME, Karnes RJ, Blute ML, Cheville JC, Sebo TJ, Kwon ED: B7-H3 ligand expression by prostate cancer: a novel marker of prognosis and potential target for therapy. Cancer Res 2007, 67:7893-7900.

34. Zang X, Sullivan PS, Soslow RA, Waitz R, Reuter VE, Wilton A, Thaler HT, Arul M, Slovin SF, Wei J, Spriggs DR, Dupont J, Allison JP: Tumor associated endothelial expression of $\mathrm{B} 7-\mathrm{H} 3$ predicts survival in ovarian carcinomas. Mod Pathol 2010, 23:1104-1112.

35. Quandt D, Fiedler E, Boettcher D, Marsch W, Seliger B: B7-h4 expression in human melanoma: its association with patients' survival and antitumor immune response. Clin Cancer Res 2011, 17:3100-3111.

36. Boland JM, Kwon ED, Harrington SM, Wampfler JA, Tang H, Yang P, Aubry MC: Tumor $\mathrm{B} 7-\mathrm{H} 1$ and $\mathrm{B} 7-\mathrm{H} 3$ expression in squamous cell carcinoma of the lung. Clin Lung Cancer 2013, 14:157-163.

37. Derynck R, Akhurst RJ, Balmain A: TGF-beta signaling in tumor suppression and cancer progression. Nat Genet 2001, 29:117-129.

38. Shen H, Zhou S, Wang J: The paradoxical role of Nrf2 in tumor biology. Crit Rev Eukaryot Gene Expr 2013, 23:37-47.

39. Luo L, Chapoval Al, Flies DB, Zhu G, Hirano F, Wang S, Lau JS, Dong H, Tamada K, Flies AS, Liu Y, Chen L: B7-H3 enhances tumor immunity in vivo by costimulating rapid clonal expansion of antigen-specific CD8+ cytolytic T cells. J Immunol 2004, 173:5445-5450.

40. Lupu CM, Eisenbach C, Kuefner MA, Schmidt J, Lupu AD, Stremmel W, Encke J: An orthotopic colon cancer model for studying the $\mathrm{B} 7-\mathrm{H} 3$ antitumor effect in vivo. J Gastrointest Surg 2006, 10:635-645.

41. Schneider T, Hoffmann H, Dienemann H, Schnabel PA, Enk AH, Ring S, Mahnke K: Non-small cell lung cancer induces an immunosuppressive phenotype of dendritic cells in tumor microenvironment by upregulating B7-H3. J Thorac Oncol 2011, 6:1162-1168.

42. Chen $C$, Shen $Y, Q u$ QX, Chen XQ, Zhang XG, Huang JA: Induced expression of B7-H3 on the lung cancer cells and macrophages suppresses T-cell mediating anti-tumor immune response. Exp Cell Res 2013, 319:96-102

doi:10.1186/1471-2407-14-602

Cite this article as: Ingebrigtsen et al:: B7-H3 expression in colorectal cancer: associations with clinicopathological parameters and patient outcome. BMC Cancer 2014 14:602.

\section{Submit your next manuscript to BioMed Central and take full advantage of:}

- Convenient online submission

- Thorough peer review

- No space constraints or color figure charges

- Immediate publication on acceptance

- Inclusion in PubMed, CAS, Scopus and Google Scholar

- Research which is freely available for redistribution 